\title{
A Study on Criminal Psychology of Juvenile Violent Murderers
}

\author{
${ }^{1}$ Zhengzhou Foreign Language School \\ *Yanzhe Wang. Email: elieenz520@qq.com
}

Yanzhe Wang ${ }^{1, *}$

\begin{abstract}
Based on Freud's psychoanalysis theory, this paper first explains the origin of the hidden criminal psychological problems in the interpretation of early experience, and draws the theoretical map of personality structure and the logic diagram of consciousness level. Then, the author further analyzes the personality structure to explain the motive force of crime and the psychological mechanism of out of control. In personality structure, ID is the foundation and power of personality structure, while ego and superego are brake valves. Personality disorder related to crime must have disharmony between motivation and braking. Finally, this paper analyzes typical cases of Zhao Chengxi and Ma Jiajue with the help of internal attachment model. The balance between psychological intention and mental strength is an important reason for people's psychological negligence, which is an important basis for psychological analysis of criminal investigation.
\end{abstract}

Keywords: Internal working model of criminal psychology, youth, violent murderer and attachment

\section{INTRODUCTION}

In China, with the in-depth development of the market economy, the social structure is gradually stratified, and the public pressure is increasing. The proportion of mental illness burden of different age groups is shown in Figure 1. The adolescent stage is a period of high incidence of psychological problems. In recent years, events such as Ma Jiajue and Zhao Chengxi have aroused a lot of attention from all walks of life. Crime is not only a social phenomenon, but also an individual phenomenon. The occurrence of any criminal act is carried out under the influence of the relevant psychological activities and psychological factors of the perpetrator. The psychological state and psychological factors that dominate the perpetrator's criminal behavior are called criminal psychology.

On the level of theoretical significance, (1) on the research content, through the literature review, the author found that few studies focused on the topic from both theoretical and practical aspects. This paper analyzes the adolescent psychology from a more comprehensive perspective and presents it with data graphs. (2) In terms of research methods, this paper uses literature review method, chart analysis method, data analysis method, case analysis method, country comparison method and other academic methods for analysis. In the field of criminal psychology, the cause of criminal psychology has always been the focus of research [1]. How to understand the mechanism of criminal psychology and effectively prevent and reduce the harm of crime is one of the important contents of criminal psychology research. Many topics discussed in Freud's psychoanalysis theory, such as subconsciousness, personality structure and intention, are worth learning from. Based on the main theory of psychoanalysis and the related terms as the secondary clue, this paper makes a deep analysis on the criminal psychology of juvenile violent murderers with the help of internal work attachment model. 


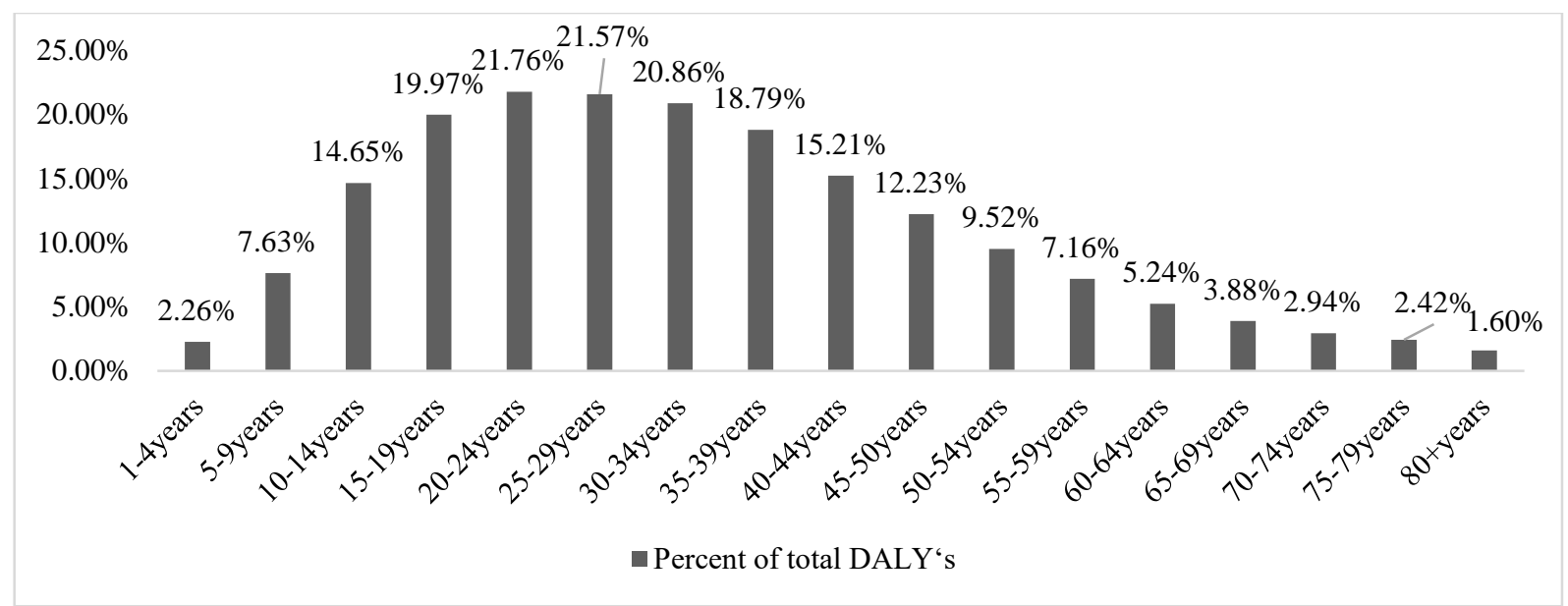

Figure 1: The proportion of mental disease burden in different ages in China

Resource: The Global Burden of Disease, Injuries, and Risk Factors Study (GBD), WHO 2013

\section{EARLY EXPERIENCE EXPLAINS THE ORIGIN OF CONCEALED CRIMINAL PSYCHOLOGICAL PROBLEMS}

In the complex psychological phenomenon of crime, we often encounter such a kind of phenomenon, that is, different from the vast majority of crimes, criminals do not evade and do not commit crimes in secret. They often openly commit serious acts of violence in broad daylight, and even commit suicide at the scene (the case of Zhao Chengxi in the United States in 2007). In the face of such crimes, people usually can't understand the criminal psychological problems of criminals. Some of them can't find the clues leading to crimes, and the judicial psychiatric identification can't find out the problem of "mental illness" (such as the magajue case in 2004 and the Breivik case in Norway in 2011), so that people can't understand the psychological reasons of criminals' crimes. The study of criminal psychology finds that Freud's psychoanalysis theory has a unique perspective in solving this kind of criminal psychological problems. This theory tells us that there is an internal connection between people's early experience and their later psychological activities [2].

Freud especially emphasized the importance of human early experience. People retain the most important childhood experience in memory, and become a part of the subconscious with the passage of time. These experiences will naturally enter the dreams of adults, and sometimes lead to the occurrence of neurosis. The treatment process is to arouse the early memory of patients and complete the psychological blank, which can be cured.

If people encounter major painful events in childhood, it is likely to cause permanent psychological trauma. "We call an experience traumatic if, in a very short period of time, the mind is subjected to the highest degree of stimulation, so that it is unable to seek adaptation in the normal way, thus permanently disturbing the distribution of the effective capacity of the mind." Trauma refers to the situation in which too strong situational stimulation exceeds the individual's psychological ability, that is, the individual is difficult to effectively handle and control, resulting in "unresponsive" or "reaction failure". Trauma is characterized by pain, frustration, suddenness and persistence. If an individual encounters a major painful event in his childhood, that is, in the early stage of his life, the individual at that time is extremely immature and extremely vulnerable, and is easily traumatized by excessive stimulation [3]. One of the results of psychological trauma is that "the pain of failure" is suppressed into the subconscious, which leads to the individual to stimulate the pathological reaction mode in the later career. Freud in the treatment of hysteria patients, through the free association and catharsis of patients, let the patients express and release the horror experience in the traumatic experience, then the symptoms can be alleviated.

The second result of psychological trauma is the stagnation of the individual's psychological development, that is, the individual's psychological activities refuse to adapt to the new changes and development, resulting in the phenomenon of "persistence" or even "retreat". The so-called "persistence" is "fixed" in the past, do not know how to get rid of themselves, so that they are divorced from the present and the future. They seem to be living in seclusion through illness, just as monks and nuns in ancient times retired to monasteries for the rest of their lives. " This kind of traumatic stimulation will make people's psychology no longer pay attention to new stimulation, learn new things and develop new abilities along with the experience, but entangle themselves in the past "failed" events, and cannot get rid of or extricate themselves from it, resulting in a psychological "knot". The so-called heart knot refers to the psychological trauma caused by some kind of external stimulation in the psychological process, and the resulting phenomenon of sticking to psychological trauma [4]. With this knot, it is 
like a knot on the baseline of individual's psychological development, which makes his future life unable to pass through or hinder his development. That is, as the days go by, a certain page in people's mind will never be turned over.

Due to the stimulation of trauma, the psychological stagnation in the early stage of development is called persistence. There is also a danger of development, that is, the parts that have already developed will encounter strong obstacles from the outside world, and will easily fall back to the initial stage of development, that is, degradation. In Freud's view, the degenerative effect refers to the phenomenon that libido retreats to the stop of development. The degeneration and depression of libido cause neurological symptoms. If only the degeneration effect, it will produce the phenomenon of inversion.

Because of the persistent and degenerative psychological problems, people have more criminal behaviors in the abnormal types of crime. For example, in 2007, Zhao Chengxi, the main culprit of the shooting on campus in the United States University, created the most tragic campus shooting incident in American history, which caused 32 deaths and 15 injuries, and committed suicide at the scene [5]. What puzzles people in this case is why he hates people around him when no one stimulates him. According to the theory of psychoanalysis, we know that people's psychological problems, especially the traumatic psychology related to emotions, often originate from early years. Therefore, the investigation of Zhao Chengxi's early experience shows that he immigrated to the United States passively with his parents when he was 8 years old. From what he said in the video tape of "crime declaration" sent by him, it can be found that his psychological problems originate from anger, which is related to loneliness and fear. Therefore, it can be inferred that he experienced the fear of the surrounding environment caused by the weak and lonely in the early stage of immigration At that time, he was unable to extricate himself from this emotion, so he accumulated more and more serious in adulthood. When he was qualified to buy a gun when he was an adult, he created the crime of venting his anger. A kind of pain of strangeness, weakness and fear broke out for 15 years, that is to use the ability of adults to realize a difficult life problem that cannot be solved independently in childhood. As shown in Figure 2, according to Maslow's hierarchy of needs theory, individuals can pursue higherlevel final needs and self-realization on the basis of meeting the primary needs stage, that is, after obtaining security requirements and belonging requirements.

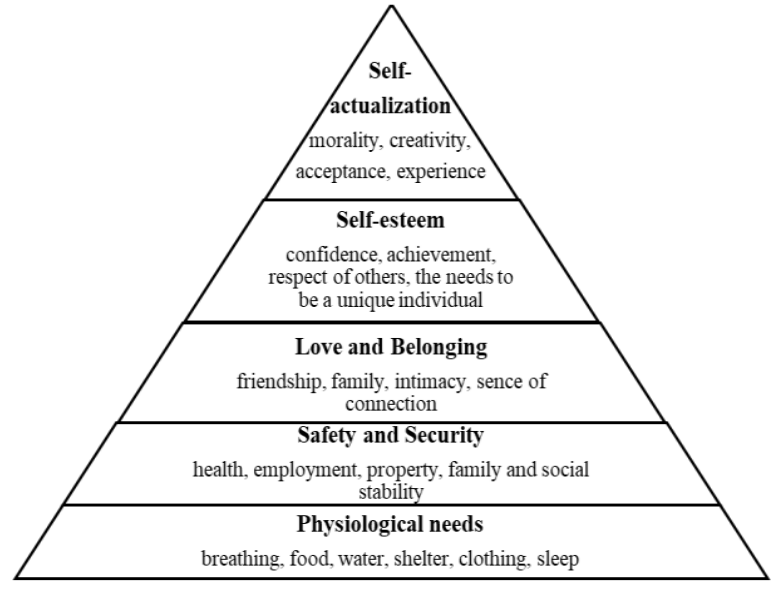

Figure 2 Maslow's hierarchy of needs

\section{Resource: Theory of Human Motivation}

There are also many child abuse criminals, some of whom have experienced the process of being abused in childhood. This kind of control and injury has caused serious psychological trauma to them. They are eager to control others when they grow up. Therefore, they realize their desire to control others and implement child abuse in adulthood. Their behavior is nothing more than a reappearance of childhood abuse, expressing their anger in this way. There are also some victims of degradation, such as: dare not see people, avoid social activities (i.e., degradation), inferiority, etc.

The Enlightenment of psychoanalysis on the existence of early trauma in the subconscious way and its influence on our life is as follows: (1) to give minors a healthy and safe environment to grow up in, to keep them away from domestic violence and major changes in life, so that they can spend their childhood in peace. Safe and healthy growth environment is very important to the mental health of minors. (2) For minors who encounter major life changes, we should timely conduct psychological counseling and comfort to prevent their psychological trauma from evolving into heart knot and minimize the harm caused by psychological trauma. (3) Pay attention to the psychological support of minors. The core of psychological support is emotional support, and the realization of emotional support is the whole process of mother's personal support. The whole society should pay attention to the process of parents' raising in person, so that children can form attachment feelings with their parents and form a sound human nature. At the same time, parents have the psychological capital of education for their children. (4) The psychological problems of minors are also social problems. When children enter kindergartens and schools, when children turn on TV and watch computers, education has brought social elements. Therefore, every teacher, every media worker and even people in all fields should form a sense of social responsibility, care and care for the physical and mental health of minors [6]. A healthy minor means a healthy next generation and a healthy society. 


\section{PERSONALITY STRUCTURE INTERPRETS THE MOVIE FORCE OF CRIME AND THE PSYCHOLOGICAL MECHANISM OUT OF CONTROL}

On the basis of his subconscious research, Freud put forward the theory of "three self" personality structure, that is, personality is composed of ID, ego and superego. The ID corresponds to the subconscious, which is made up of natural, instinctive and desire self. ID belongs to the lowest and most dynamic energy system in personality structure. Its core content is libido, which is closely related to human survival and reproduction. It pursues happiness and releases tension according to the principle of happiness. The self-corresponds to the level of consciousness. It is a perceptual system formed by the influence of the external world from the ID. it follows the principle of reality [7]. In order to better meet the requirements of the ID, the external authority is judged according to the situation, and selective cooperation, adaptation and control of the ID appear. The self has the function of intermediary and adjustment. Intermediary means that the self should revolve among the three "monarchs", namely, the external authority, the superego and the ID, like a servant on both sides; adjustment refers to having to restrain the ID in order to adapt to the external world and cooperate with the superego. Superego is the part of personality structure that is far away from ID, and even more represents a kind of "collective will". The most rational part, with human conscience and ideal, follows the rational principle of morality, so as to examine ID, guide self and pursue perfection. Freud believed that a person's ID, ego and superego should be a unified, harmonious and balanced organizational structure. When the three conflicts, people will be in a state of imbalance and psychological diseases will appear.

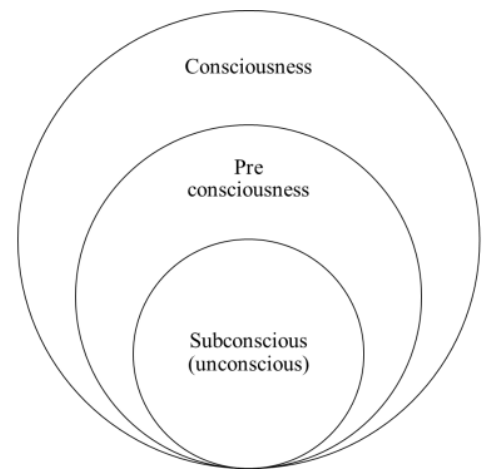

Figure 3 Freud's theory of consciousness level

Resource: Die Traumdeutung

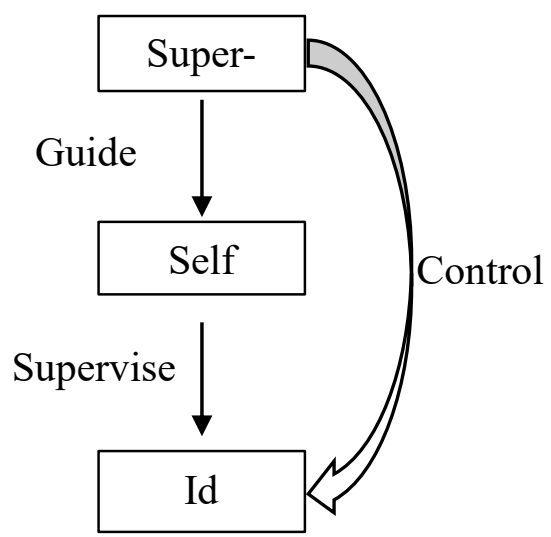

Figure 4 Freud's theory of Personality Structure

Resource: The Ego and the Id

The problem is that they are not independent or parallel, but have a sequential and progressive process. Among them, ID is the beginning of personality development, and it is also the personality state of people in their early years. This kind of natural, instinctive and desirous self is easy to be restrained and restrained by the self from external authority because of following the principle of happy egoism. This process takes place in the early stage of human growth. Therefore, people are more likely to feel frustrated in the early years because of the conflict between ID and ego. This kind of setback and result is just a group of early adult consciousness activities, with the development of personality and become subconscious [8].

As mentioned above, the subconscious is the theoretical cornerstone of the psychoanalysis school. It refers to the consciousness that people need to hide or cover up. It is at the deepest level of consciousness and is the internal driving force of human activities. It is the foundation of all conscious activities in adulthood Because its depth is naturally superimposed and masked, its owner is often ignorant of it. Some people think that because Freud discovered the subconscious, we find that we are not the master of the universe (Copernicus broke the theory of geocentrism), nor the master of all things (Darwin pointed out that man evolved from monkeys), nor even ourselves Human (Freud thought that human behavior could not escape the domination of irrational force subconscious).

The subconscious corresponds to the ID in the personality structure, and it also follows the happy principle (or the only music principle). For people, the "Id" in the three self-structure of personality accounts for the highest proportion, and the demand for human instinct and desire is the greatest. It is human nature to love to eat, play, have fun and be curious. And this natural desire will be naked in children's dreams in the early years of human beings. Children will often realize their needs through dreams when they can't meet their needs. However, as people grow older, they have the intervention of pre consciousness and consciousness, which correspond to 
the later self and superego. Pre consciousness is a kind of conscious activity between consciousness and subconsciousness. Freud thinks that it has a certain checking function, which is responsible for filtering and blocking the over active elements in subconscious into the scope of human consciousness. He also compared "consciousness" to a small "reception room" adjacent to the "big front room" (subconscious). Obviously, consciousness is more faced with the outside world, and the relationship with subconscious is still separated from the pre consciousness (inspector). This kind of contact is not smooth, which leads to the conscious activities more inclined to cater to the outside and ignore the internal, and even cover up the internal, so the conscious activities are more likely to form two forces of self and superego, acting according to the principles of reality and rationality [9]. This means that with the development of personality, the ego and superego come from behind and control the ID. In the same way, in the growth of human beings, due to the gradual strength of self and superego, the ID can no longer be satisfied at any time, can no longer easily feel happy, cannot vent energy, and cannot let go, so there is a psychological crisis in growth.

In real life, people's growth is subject to etiquette, rules, constraints, knowledge and other education process, which will be different due to the differences between parents and teachers. For example, some parents or teachers excessively suppress and interfere with children's nature, and they are too harsh to suppress the "Id". They design education according to their own ideals rather than human nature, which will create a strong external force for children [10]. For example: Tiger mother and wolf father's parenting style lead some people from small to big to hear and see is severe and merciless, in their mind, the relationship between people is the demand and realization, is the goal and the result, there is no emotion, no need for compassion and tenderness, not to mention kindness. As a result, their social behavior and personality are severe and merciless. Yao Jiaxin's case of murder after a traffic accident in 2010 has such psychological problems. When Yao Jiaxin bumped into a young woman, his first thought when he got out of the car to check on the victim was that he was worried about "being difficult to handle". He did not have a trace of hesitation in his mind. He did not think that a woman would have an elderly parent and a baby to be fed. What he had in mind was how to avoid "aftereffects", so he killed people in the simplest way. This kind of person is not only callous to outsiders, but also demanding and even forcing himself. Many people with compulsive personality often have an extremely strict father or mother in their early years. People with this compulsive personality are more likely to have psychological disorders in their adult life, such as anxiety because they can't reach the expected goals, and angry because their subordinates can't reach the goals. Therefore, although such people have a high or strong level of ability, they are more likely to have psychological obstacles, and their extreme performance is criminal behavior.

Freud's subconscious theory and personality structure theory describe the psychological problems in human development from a unique perspective, that is, each person's personality development is the progressive emergence and development of "three selves". This process has not only the sequence of time, but also the hierarchy of space; there are both the power source (ID), and the braking system (ego and superego). Without understanding the mystery of personality formation, it is difficult to understand the origin of various abnormal psychological manifestations, including serious criminal psychological phenomena.

\section{TYPICAL CASES OF INTERNAL ATTACHMENT WORK MODEL}

Ma Jiajue and Zhao Chengxi may not have a secure attachment relationship in their childhood. Their internal working model may be: they are not cute, others are not trustworthy, and they should be self-satisfied. From the data, we find that Zhao Chengxi and Ma Jiajue have many similarities in their childhood: they are good at school, introverted, lack of playmates and little attention from their parents. According to Bowlby, the internal working model is the main source of coherence between an individual's infancy attachment experience and his later feelings and behaviors, that is, the internal working model is stable. The internal working model formed by $\mathrm{Ma}$ Jiajue and Zhao Chengxi in the early stage has a profound influence on their thinking and behavior in adulthood. When I was in college, I seldom asked for money from my family. I asked for it once in a while. According to Ma Jiajue's sister, whenever she asked Ma Jiajue whether he was short of money, he would shake his head very briskly. In Ma Jiajue's attachment behavior system, his mother and sister, who were closest to him, would not pour out their troubles and seek support. Zhao Xianglin, Zhao Chengxi's mother, recalled that her son rarely spoke, and even when he spoke, he only whispered a few words. He never looks directly at others. He is like living in his own world forever. At home, Zhao Chengxi always sits quietly in front of the computer typing, never sharing his works with his family.

Bowlby emphasizes that attachment is a lifelong phenomenon from cradle to grave. Other researchers have found that adult individuals can also form attachment relationships from early mothers and children with close objects such as relatives, friends and partners. Adult attachment behavior patterns such as proximity maintenance, separation anxiety, and using the other as a safe haven and a safe base for free exploration may also occur in intimate relationships. Collins \& read put forward a more meaningful internal activity model, namely multiple working models. The model considers that the internal activity model of an individual is 
hierarchical. The general model is at the top level (taking the mother child relationship established in infancy as the template), a special type of relationship mode (such as family members and peers) is in the middle layer, and the specific relationship mode (such as father and spouse) is at the bottom, that is to say, adults can form multiple attachment relationships. Freeman believes that in adolescence and adulthood, individuals transfer their initial attachment from their parents to their peers. There are many different sources of support for safe attachment adolescents. In contrast, refusal adolescents don't see their parents as an important source of emotional support. Nearly a third of this type of adolescents have excessive independence and report no significant support. These results indicate that whether there is a close friend or partner in adulthood has a great influence on the individual's psychological activities.

In September 2000, accompanied by his father, Ma Jiajue reported to Yunnan University of his choice. Every freshman is full of good hope for the future, and Ma Jiajue is no exception. Ma Jiajue, who has few words, tries to change his isolated personality and integrate into university culture. Ma Jiajue reported to the sports department, but was eliminated. He also tried to be an activist in the crowd, but his poor expression made him a laughing stock for others. Pursue a girl, after being rejected, think others despise him. He only contacts with a few students and fellow villagers, and has not formed a deep relationship. During the interrogation, the police asked: Why did you kill people? He said: I think I failed too much. Police asked: why do you think you failed? He said: I think they all look down on me. From the above dialogue, we can see that Ma Jiajue thinks that he is not worthy of love, and other people are not worthy of love. The long repression finally exploded in the final event. At this time, in Ma Jiajue's internal work model, his parents are working hard for their livelihood, and they will not think of his son's distress; his brothers and sisters have set up families and have no time to take care of him, and he also chose to refuse as a child; his most valued good friend seems to have betrayed him. In the face of great psychological setbacks, he did not turn to anyone for help, but chose aggressive coping style.

When Zhao Chengxi first entered Virginia Tech, he also tried to integrate into the new environment. He majored in business information technology when he first entered school, but decided to transfer to English department when he was a sophomore. He firmly believed that he could become a famous writer. His sister once found a rejection letter from a publishing house. Since receiving this letter, Zhao Chengxi has become more depressed and autistic, and his English score has dropped from "B" to "d". He felt that no one understood him, no one could see his talent, and his anger grew in silence. In this way, he lives alone in a six-person bedroom, among 26000 students at Virginia Tech. He ate alone in the restaurant and went to bed early at 9 p.m. In the morning, he often wakes up before dawn, and then sits in front of his computer all the time, never greeting his roommate. It can be seen that Ma Jiajue and Zhao Chengxi were in a state of psychological depression for a long time, and felt the humiliation and injustice from society and others, and finally reached the "collapse point".

\section{CONCLUSION}

\subsection{Summary}

Freud's psychoanalysis not only explores the mystery of human deep psychological activities, but also provides a unique perspective for the study of criminal psychology. In the personality structure, ID is the foundation and motive force of personality structure, while ego and superego are the control and brake valve. The disharmony of the development of "three sels" will inevitably lead to the disharmony between the motive force and the braking relationship of human personality, which will lead to the danger of life. Subconsciousness is also related to people's inner intention. The conflict of force and energy between different intentions will lead to mental power balance, which is exactly the important reason for people's psychological fault or behavior out of control. It also provides clues to explore people's inner activities from external behavior signs, which is an important basis for psychological analysis of criminal investigation.

\subsection{Outlook}

Due to the limitation of space and data, the analysis of the case of Zhao Chengxi's campus shooting and Ma Jiajue's murder can only be based on the limited written materials left by the murderers and the interviews with their relatives, classmates and teachers. These data are not original data and have been selected subjectively by researchers and interviewers. Therefore, researchers should find the similarities and differences of the parties from similar events, and analyze them with the internal working model of attachment, so as to find more solid arguments for the event. The author will further analyze in this direction in the future.

\section{REFERENCES}

[1] Stuerup G K. THE PSYCHOLOGY OF MURDERERS. [J]. 1964, 54:27.

[2] Koludrović M, Korbar K, Rak D, et al. Psychopathic murderers and their victims[J]. 1986, 43(3):198.

[3] Hays J R, Solway K S, Schreiner D. Intellectual characteristics of juvenile murderers versus status offenders[J]. Psychological Reports, 1978, 43(1):80-82. 
[4] Pezza P E, Bellotti A. College campus violence: Origins, impacts, and responses. [J]. Educational Psychology Review, 1995, 7(1):105-123.

[5] Heilbrun K, Dvoskin J, Heilbrun A. Toward Preventing Future Tragedies: Mass Killings on College Campuses, Public Health, and Threat/Risk Assessment[J]. Psychological Injury \& Law, 2009, 2(2):93-99.

[6] Canter D. Criminal Psychology: Topics in Applied Psychology[J]. 2008.

[7] Daniel A. Martell. Review of: Applied Criminal Psychology: A Guide to Forensic Behavioral Sciences[J]. Journal of Forensic Sciences, 2010, 55(1):282-282.

[8] Mark Shevlin, Professor, Hyland, Philip. Application of bifactor models in criminal psychology research: a guide to researchers[J]. Journal of Criminal Psychology, 5(2):65-74.

[9] keqin Ren, Bochun Liu. On Interrelation between Criminal Psychology and Other Criminal Science of Laws[J]. 2003, 39(5-6):279-279.

[10] John K. Holton, Michael Rutter, Henri Giller. Juvenile Delinquency: Trends and Perspectives[J]. Contemporary Sociology, 1985, 14(4):460. 